\title{
ECONOMICS
}

\section{SYSTEM MODEL OF ANALYZING INTERNATIONAL TRADE RISKS FACED BY A BUSINESS ENTITY UNDER ECONOMIC UNCERTAINTY}

\author{
O. Martyanova ${ }^{1}$ \\ DOI: http://doi.org/10.15350/L_21/3/1
}

\begin{abstract}
The paper sheds light onto the core directions for methodology development of international trade risk analysis under economic uncertainty. The author proposes a model of risk analysis in the system of efficiency management of international trade of a business entity. This model provides a comprehensive approach to the problem, thus reducing loss probability in the event of occurrence of any adverse circumstances that a business entity might face in international trade. The model is well grounded on the system approach and mathematic modelling in economics.
\end{abstract}

Keywords: risk, international trade, risk factors, systematization, methodology, strategy, analysis model, efficiency, system approach.

Risk management faced by business entities involved in international trade acting as a form of international trade, has recently been approached from the pragmatism perspective, when experience is viewed as a core methodological principle, while practical efficiency of theories and scientific approaches to the resolution of the problem was taken as the truth criterion. Despite all the significance of risk analysis in the sphere of international trade of economic business entities, the research into risk analysis was carried out beyond the methodology, through the application of a "methodological desert" estimate [3, p. 10]. Under this approach the methodological tool ware used for strategic risk management of the international trade should rely on fundamental factor analysis exerting a direct or indirect impact on the level of risk, as well as on the practical skills of a decision maker.

We believe that for the purpose of risk analysis accompanying international trade of business entities, it is appropriate to employ the system-based

\footnotetext{
1Olga Martyanova, Candidate of Economic Sciences, doctoral candidate The Orel State University of Economics and Trade, Russia.
} 
methodology. This approach, in addition to theoretical concept development on the contents characteristics of the strategic risk management of international trade, allows improving the methodological tool ware of implementing programs for risk level prognostication. The solution of this scientific problem is of vital importance particularly after the foreign countries imposed sanctions against Russia, which scaled up the risks associated with international trade of Russian business entities on the global market. This fact necessitated reconsideration of conceptual framework of policy exercised by Russia in the sphere of international trade, since the companies ignoring real market conditions and business processes context will inevitably end up bankrupt.

In this respect it is necessary to define the concept of risk in international trade of a business entity. The term "risk" may be traced back to Greek "rixikon", meaning navigating among cliffs [3, p. 11]. The finance and credit dictionary defines risk as loss probability as a result of financial, foreign exchange or lending transactions [2, p. 850]. G. Bets defines risk as a probability of loss meaning specific loss or damage [1]. In the research objectives of transactions L.I. Lopatnikov defines risk as a degree of inconsistency between different probable results [5, p. 242]. A wide number of definitions for this notion proves the lack of unanimity among scientists in relation to its meaning. Some definitions focus on the reasons for risk emergence, without defining its subject matter, while others focus on its contents and neglect loss probabilities specified by the conditions of international trade agreements.

However, every time under uncertain economic situation, whenever a decision maker knows, that the situation under study might have a different outcome, there is a risk. Thus, a decision maker is apt to prognosticate each of the possible outcomes based on his/her experience. In the sphere of international trade risk may be defined as a probable risk cost under adverse development of business processes. Therefore, based on the definition stated above, risk analysis of international trade of business entities aims not only to level these risks down, but also to define economic consequences of implementing midterm international trade projects in order to justify strategic solutions, taking into consideration financial and non-financial factors. Thus, risk analysis in the sphere of international trade should facilitate transactions, and additionally implement international trade strategy, ensuring sustainable development of a company.

Since international trade risks depend on the condition of the international market, it is necessary to determine the key factors of risks, which enable a business entity to adapt to the global rules of world commerce. The classification of risk factors, exerting both direct and indirect impact on the loss probability under adverse economic situation for the company is one of the components of system approach methodology to risk analysis in terms of international trade. 
Taking into consideration the importance of typology as a component of the system methodology under Russia's integration into unstable world economy, which results in the increase of the impact of global threats onto the operation of a business entity in the sphere of international trade, it is deemed appropriate to classify risk factors in order to define those, that can be influenced by a business entity, and those, that merely reflect the risks faced in the global economy (Fig.1).

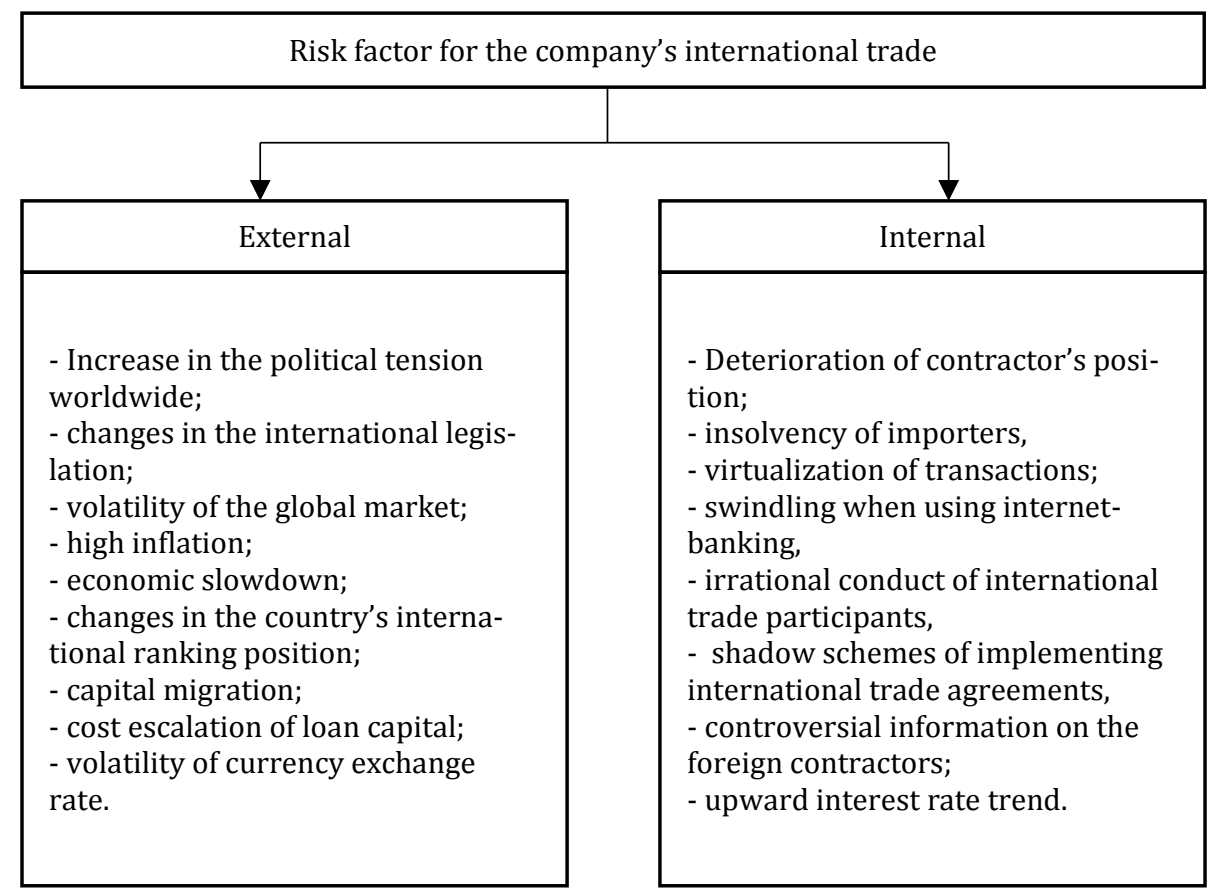

Fig. 1. Risk factors in the company's international trade Source: Compiled by the author using [3, p. 12]

The analysis of risk factors in the international trade of a business entity presented in Fig.1 reveals strong interrelation between internal and external factors. This is the result of Russia's integration in the world economy enhancing the impact of changes and global trade risks on the operation of economic entities in the sphere of their international trade. The core global factors of international trade risks determining the company's activity in the sphere of international trade should are as follows: political situation in the world, financial and economic crises causing instability of the world market, which results in aggravation of competition, volatility of market prices and materials, increase of swindling as a result of international trade and internet banking intensification. All these require improvement of regulatory and legal framework governing world 
commerce. Russia's membership in the WTO is another risk factor particularly for non-competitive players of the market economy. This is because Russian companies involved in international trade are bound to abide by the rules of the global trade.

At present the companies involved in international trade represent open systems, each comprising an array of numerous components interrelated with the global market. Ever changing conditions of international trade, stakeholders and participants involved in overseas commerce represent the risk source for the company. In practice, the efficiency of the company's international trade is defined by its prompt and adequate response to the changes in the external environment, which requires the ability to reveal essential risk factors in international trade, to prognosticate their changes and preliminarily estimate the potential conditions of the global market, in which the economic entity will operate in the future. The problem, however, is that it is impossible to take into consideration the impact of all the factors, therefore, the research into external environment should focus on those factors, which are bound to reduce the level of international trade risks.

Thus, the risk analysis in international trade of a business entity should take into consideration internal factors and a wide array of external risk factors changing depending on the development of international economic relations and defining the current trends in the world trade.

Multiple factors of risk formation in the sphere of international trade of a business entity determine the necessity for their systematization in the framework of a system approach to international risk management, depending on the actual condition of the national economy and its international competitiveness. According to the estimate of foreign specialists the use of 40 criteria results in up to 220 types of risks [3, p. 12]. Therefore, it is deemed appropriate to classify risks in international trade in compliance with the typology in international economic relations, which will provide a generalized model of risks of the company's international trade adequate with the modification of the global process of reproduction (Table 1).

Systematization of risks in international trade made it possible to single out different types of risks as well as extend risk typology in international economic relations. Thus, in the current situation the exchange risk can's be defined as the loss of value as a result of exchange rate fluctuations in the currency of the contracting international parties. It also includes risks incurred by the bank, acting as intermediary in the currency transactions of the companies carrying out intentional trade activities. 
Table 1

Systematization of risks in international trade of companies

\begin{tabular}{|c|c|}
\hline $\begin{array}{l}\text { Type of international } \\
\text { trade risk }\end{array}$ & Characteristics of international trade risk \\
\hline Foreign currency risk & $\begin{array}{l}\text { Hazard of monetary loss as a result of fluctuation in the exchange rate } \\
\text { occurring between signing of an Agreement and its fulfillment [2,p. 850] }\end{array}$ \\
\hline Inflation risk & $\begin{array}{l}\text { Risk of potential depreciation of profit gained from international trade } \\
\text { transactions due to the escalation of inflation }\end{array}$ \\
\hline $\begin{array}{l}\text { Information security } \\
\text { risk }\end{array}$ & Risk of loss caused by the use of information technology \\
\hline Competitive risk & $\begin{array}{l}\text { Probability of loss as a result of low competitiveness of the product pro- } \\
\text { vided by the company involved in international trade }\end{array}$ \\
\hline Moral risk & $\begin{array}{l}\text { Probability of loss as a result of a foreign contractor's pass on its obliga- } \\
\text { tions in relation to international trade agreement to a third party with } \\
\text { the right to change the conditions of the agreement fulfillment }\end{array}$ \\
\hline Conduct risk & $\begin{array}{l}\text { Risk of irrational conduct as a result of adverse consequences of a cer- } \\
\text { tain events or a group of events }\end{array}$ \\
\hline Legal risk & $\begin{array}{l}\text { Probability of loss as a result of incompatibilities in the Russian legisla- } \\
\text { tion and the standards of international law }\end{array}$ \\
\hline Ranking risk & $\begin{array}{l}\text { Risk of subjective evaluation of a company's activity in the sphere of in- } \\
\text { ternational trade carried out by a consultancy agency }\end{array}$ \\
\hline Reputation risk & $\begin{array}{l}\text { Probability of the reputation loss experienced by a prudent player of in- } \\
\text { ternational trade transactions }\end{array}$ \\
\hline $\begin{array}{l}\text { Internet commerce } \\
\text { risk }\end{array}$ & $\begin{array}{l}\text { Probability of loss as a result of the leak of data or processing of data } \\
\text { related to international trade agreements }\end{array}$ \\
\hline $\begin{array}{l}\text { Risk of shadow trans- } \\
\text { actions }\end{array}$ & Risk of loss as a result of involvement in illegal transactions \\
\hline Market risk & $\begin{array}{l}\text { Probability of risk as a result of unfavorable changes in the conditions of } \\
\text { the international trade agreement caused by the changes on the global } \\
\text { market }\end{array}$ \\
\hline Country risk & $\begin{array}{l}\text { Risk of loss as a result of the foreign contractor's default from its obliga- } \\
\text { tions }\end{array}$ \\
\hline Strategic risk & $\begin{array}{l}\text { Risk of loss as a result of incorrect international trade strategy of a com- } \\
\text { pany }\end{array}$ \\
\hline
\end{tabular}

Compiled by the author using [3, p. 13]

The typology analysis of international trade of business entities makes it possible to develop recommendations in order to systematize analysis of these factors. This system is bound to facilitate making both prompt and strategic decisions based on the information which takes into consideration the impact exerted by internal and external risk factors onto the efficiency of a business entity operation in the sphere of international trade. Competitive risk escalating with the growing number of foreign companies operating in Russia, and an increase in the share of foreign capital owned by the Russian economic entities, may stimulate unhealthy competition on behalf of foreign contractors, thus discriminating Russian contractors of international trade agreements.

Violation of the principles ensuring equal conditions for operating on the global market, including a foreign contractor's refusal from liabilities recognition, termination of payment, reconsideration of the business conditions, which is the subject of the country risk, makes Russian companies develop the system 
for international contractors' development, conditions of international trade agreements. These actions are bound to reduce the level of the company's information risk, which increased as a result of Russia's integration in the global information community. In this context Russian partner-companies involved in international trade face unauthorized access to the information on the Russian participants of international trade agreements via e-technologies, as well as allocating incomplete information on the foreign contractors. Acquiring detailed information a foreign partner allows avoiding moral risk which increased dramatically in international transactions between euro-zone countries and Russia in the context of the economic crisis. No company is going to enter into contractual relations with a foreign contractor which transfers information about the participants of the transaction and its conditions to the third parties. Therefore, the analysis results of potential partners allow avoiding irrational conduct of international contractors caused by their expectation of negative consequences from international business processes. This is bound to keep to a minimum the impact of the conduct risk on the company activity in the sphere of international trade.

It is worthwhile mentioning that the efficiency of the company's international trade depends on the strategy pursued by the company. Any strategic blunders will result in the increase of strategic risks, i.e. non-real predictive estimates of the fulfillment of the international trade agreement, false choice of the foreign contractor. For this reason there is an increase in the risk of shadow transactions. This type of risk manifests itself in making agreements with business entities registered in the offshore area, which in its turn increases the loss probability of business reputation of a company involved in international trade, i.e. causes reputation risk loss and furthermore, ranking risk loss as well.

While developing the international trade strategy it is risky to neglect external factors, exerting an impact on the efficiency of a business entity's activity in the sphere of international trade. This may increase the loss probability caused by the changing situation on the global market, which in its turn requires amendments of the international trade agreements, which turn to be more unfavorable for the company than the initial ones. Thus, the degree of the market risk increases. In the view of the foregoing, we apt to present an economic model of risk analysis in efficiency management of a business entity involved in international trade. This model comprises three stages.

The first stage - collection and processing of the current data on the risks in the sphere of international trade. During this stage we reveal the factors of international trade risks, identify them, prognosticate risk scenarios depending on the development of the global market and the company under study.

The second stage presumes analysis and estimate of risk in the sphere of intentional trade of a company. This stage includes selection of risk assessment 
methods, making prognosticative estimates of the degree of international trade risks and the analysis of the risk impact on the efficiency of the company's international trade.

The third stage implies making a decision concerning the applied model of risk management based on the results of the intentional trade analysis in order to reduce to a minimum the impact of these risks on the efficiency of a company's international trade. This stage includes selecting a criterion for the decision making, developing recommendations in order to reduce the degree of international trade risk and providing grounds for the selection of the model of risk management.

In addition to the estimate the developed model allows prognosticating the level of international trade risks, which is viewed as one of the applied aspects of the contemporary economic analysis of a company's international trade. Predictive risk estimates represent the outcome of the prospective analysis, based on the current data concerning the state of internal and external factors of the economic environment. Provided that a decision maker has all the data necessary and sufficient to make judgments on the stability of a certain segment of international trade market or its probable dynamics, it is deemed possible to analyze the alternative scenarios for the development of international trade risks. As a result of this analysis we obtain a strategy, which allows reducing the degree of international trade risks in a company.

It is worthwhile mentioning that different methods and approaches may be used in order to analyze and estimate the impact of different factors on the degree of international trade risks. The choice of options coming down to compromising between the risks and the expected profit may be carried out using Wald of Savage criteria. These criteria are described in detail in [6, p. 102]. The practical implementation of the decision making approach under economic uncertainty using the MiniMax loss matrix is as follows. Upon developing a new upmarket beer brand the brewing company intends to export it without undertaking a preliminary exploration of the demand, which can be bad, satisfactory or good on a foreign market. Depending on the demand and the selected level of beer output, the exporter may gain the following profit (Table 2) in the second quarter of 2017.

Table 2

Predicted profit level gained by the exporter (in thousand euro)

\begin{tabular}{|l|c|c|c|}
\hline \multirow{2}{*}{ Demand level } & \multicolumn{3}{|c|}{ Output level } \\
\cline { 2 - 4 } & High & Medium & Low \\
\hline Good & 441 & 189 & 126 \\
\hline Satisfactory & 126 & 252 & $(126)$ \\
\hline Bad & $(63)$ & $(15.75)$ & $(31.5)$ \\
\hline
\end{tabular}


In order to minimize the maximum possible loss under uncertainty situation when selecting the level of output from the alternatives available we will elaborate the following risk matrix (Table 3 ).

Table 3

Risk matrix on the options of alternative decisions (in thousand euro)

\begin{tabular}{|l|c|c|c|}
\hline \multirow{2}{*}{ Demand level } & \multicolumn{3}{|c|}{ Output level } \\
\cline { 2 - 4 } & High & High & High \\
\hline Good & 0 & 252 & 315 \\
\hline Satisfactory & 126 & 0 & 378 \\
\hline Bad & 47.25 & 0 & 15.75 \\
\hline
\end{tabular}

The analysis of Table 3 proves that in accordance with MiniMax Savage criterion, it is optimal for the exporter to refer to a high level of output, as this option is characterized by the minimum amount of maximum loss.

If a company needs to decide on the retail price of one liter of a new beer brand, it is necessary to select the alternative under uncertain economic conditions using Wald criterion. This is a precautionary approach, because it targets a decision maker at the worst-case outcome, as it recommends to favor the option when the minimum reward will be the maximum.

In the case under study, due to uncertain situation on the global market the demand for the beer sold for one out of four possible prices may be good, satisfactory or even bad.

Each of the possible options will result in the profit gain. The profit values run as follows (Table 4).

Table 4

Matrix of effects on the options of alternative solutions

\begin{tabular}{|l|c|c|c|c|}
\hline \multirow{2}{*}{ Demand level } & \multicolumn{4}{|c|}{ Selling price, euro/l } \\
\cline { 2 - 5 } & 14.8 & 22.2 & 29.6 & 37.0 \\
\hline Good & 18,500 euro & 22,200 euro & 14,800 euro & 11,100 euro \\
\hline Satisfactory & 7,400 euro & 11,100 euro & 9,169 euro & 6,586 euro \\
\hline Bad & 5,099 euro & 5,872 euro & $(7,400)$ euro & $(3,700)$ euro \\
\hline
\end{tabular}

When the selling price equals 14.8 euro/l, the minimum profit amounts to 5,099 euro, when the selling price equals 22.2 euro/l, the guaranteed profit amounts to 5,872 euro, when the selling price equals 29,6 euro/l and 37 euro/l respectively the exporter incurs losses. Thus, according to Wald criterion the best selling price is 22.2 euro/l.

Wald criterion (maximin), as well as Savage criterion (MiniMax) are the criteria of radical pessimism which mean minimization of maximum losses.

However, in order to minimize possible risks when establishing a selling price for a new product, it is not enough to have an idea on the current situation on the global market, it is also necessary to prognosticate the dynamics of the 
product at least in the short run. In order to solve this problem it is deemed appropriate to apply probability models including Markovian processes as they allow obtaining concrete results under economic uncertainty.

A more detailed description of Markovian processes application when evaluating international trade risks based on the data provided by the company involved in international trade is provided below. Since the export upmarket beer may be in one of four mutually exclusive conditions, this statement may be presented as follows:

$s_{1}$ - seller dominates the market, when the demand exceeds supply;

$s_{2}$ - customer dominates the market, when the supply exceeds demand;

$s_{3}$ - market equilibrium, when demand equals supply;

$s_{4}$ - commissioner dominates the market, when the market situation is determined by the policy implemented by a commissioner.

According to the data gained by the company as a result of research into the market of premium class beer, its state in the future will depend on the current state of the beer market. Herewith, it has been proved that the market randomly transfers from one condition to another at any given point in time. Changes in probability density of transfers from one condition into another are minor all through the period under study and are defined by the following matrix:

$$
\mu=\left(\begin{array}{llll}
0 & 3 & 1 & 0 \\
4 & 0 & 0 & 5 \\
0 & 2 & 0 & 3 \\
1 & 6 & 0 & 0
\end{array}\right)
$$

In order to define risks of entering the overseas market with a new beer brand, we will prognosticate its condition in the short run.

It follows from the conditions that system $S$ viewed as an international trade market of a premium class beer features a discrete homogeneous random process with continuous time. Therefore, the random process occurring in system $S$, may be considered a Markovian process tending to have no aftereffect [4, p. 7]. The process is discrete due to the fact, that the set of states of the analyzed system $S$ is finite $\left\{s_{1}, s_{2}, s_{3}, s_{4}\right\}$. Since the transfer of system $S$ from one state into another may occur at any random point in time, then it can be qualified as Markovian process with continuous time.

The analysis of discrete Markovian processes occurring in system $S$ should be carried out using a graph of its states, presented in Fig. 2. 


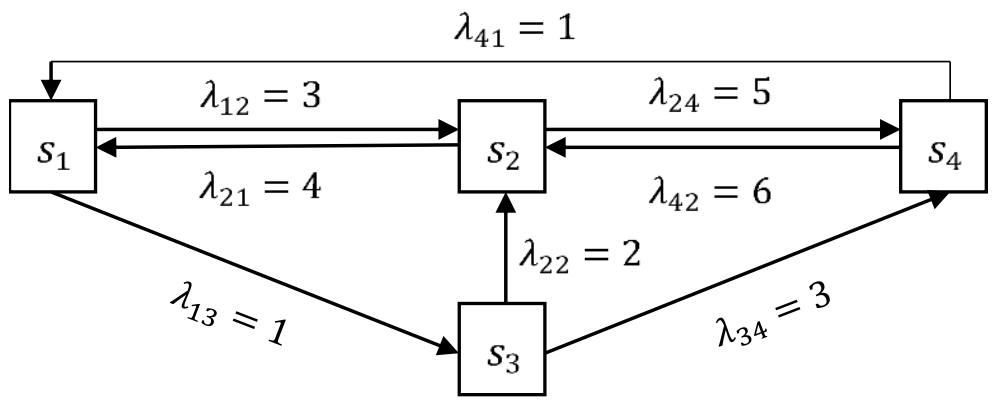

Figure 2 - Mapped state graph of a participant involved in international trade

Analysis of the graph proves that system $S$ is ergodic, because it may transfer from any current state to any other state for the finite number of steps. If system $S$ is ergodic, the number of its states is final and all the flows of events fostering transfers of system $S$ from one state to another are basic, there are final probabilities of state [4, p. 115]. The analyzed system $S$ meets all the above mentioned conditions, there are final probabilities of its state $p_{1}, p_{2}, p_{3}, p_{4}$ which are not affected by the time or its initial state. These final probabilities contain data on short-term prognosis of the condition of international trade market of the premium class beer.

Let us make a homogenous system of $n=4$ algebraic linear equations for the following unknown $p_{1}, p_{2}, p_{3}, p_{4}$.

$$
\left\{\begin{array}{l}
-4 p_{1}+4 p_{2}+p_{4}=0 \\
3 p_{1}-9 p_{2}+2 p_{3}+6 p_{4}=0 \\
p_{1}-5 p_{3}=0 \\
5 p_{2}+3 p_{3}-7 p_{4}=0
\end{array}\right.
$$

Let us carry out a few transformations within the system (1). As a result we will get the following:

Whence, it follows that

$$
\left\{\begin{array}{l}
p_{4}=4 p_{1}-4 p_{2} \\
3 p_{1}-9 p_{2}+2 p_{3}+6 p_{4}=0 \\
p_{1}=5 p_{3} \\
5 p_{2}+3 p_{3}-140 p_{3}+28 p_{2}=0
\end{array}\right.
$$

$$
\left\{\begin{aligned}
p_{4} & =20 p_{3}-4 p_{2}, \\
3 p_{1} & -9 p_{2}+2 p_{3}+6 p_{4}=0, \\
p_{1} & =5 p_{3} \\
p_{2} & =4.1515 p_{3} .
\end{aligned}\right.
$$

By substituting the expression for $p_{2}$ into the first equation, we will find $p_{4}:$ 


$$
\left\{\begin{aligned}
p_{4} & =3.3939 p_{3}, \\
3 p_{1} & -9 p_{2}+2 p_{3}+6 p_{4}=0 \\
p_{1} & =5 p_{3} \\
p_{2} & =4.1515 p_{3} .
\end{aligned}\right.
$$

Therefore the general solution of the system (1), which depends on a free parameter $p_{3} \in[0.1]$, and represents an array of particular solutions may be represented as follows:

$$
\left(p_{1}=5 p_{3} ; p_{2}=4.1515 p_{3} ; p_{3} ; p_{4}=3.3939 p_{3}\right) .
$$

On the basis of particular solutions (2), it is necessary to find the one that would meet the normalizing condition:

$$
p_{1}+p_{2}+p_{3}+p_{4}=1
$$

By substituting values $p_{1}, p_{2}, p_{4}$ found above into the equation (3), we will get the following equation:

$$
5 p_{3}+4.1515 p_{3}+p_{3}+3.3939 p_{3}=1 .
$$

Whence,

Then

$$
p_{3}=0.0738
$$

$$
\begin{aligned}
& p_{1}=5 \times p_{3}=5 \times 0.0738=0.3690 ; \\
& p_{2}=4.1515 \times p_{3}=4.1515 \times 0.0738=0.3064 ; \\
& p_{4}=3.3939 \times p_{3}=3.3939 \times 0.0738=0.2508
\end{aligned}
$$

Thus, the short-term prognosis of the state of international beer market shows a high probability of deficit (p_1 $0.3690>$ p_2,p_3,p_4) in its premium class segment for the year to follow. Under the situation of a deficit the demand for the product will significantly exceed supply. It means that a company should take a risk and enter the global market with its new product.

Systematization of results of the carried out analysis enables us to make the following conclusions:

1.The economic model of risk analysis in efficiency management of an international trade of a business entity suggested in the paper, allows making estimates as well as prognosticate the degree of international trade risks being one of the applied aspects of contemporary economic analysis in the international trade of a business entity. Predictive estimates of the risk level allow a decision maker to determine the company strategy based on the current situation on stability or probably dynamics of a certain segment of international trade market and to analyze the alternative scenarios for the development of international trade risks. As a result of this work it is possible to develop a strategy, which is bound to reduce the risk level of the company's international trade.

2.Before establishing a selling price for a new product in order to minimize the probably risks, it is not enough to be aware of the current situation on 
the global market, it is necessary to prognosticate the dynamics of the new product on the market at least in the short run. In order to solve this problem, we suggest using probability models, including Markovian processes, as they enable gaining concrete results under economic uncertainty.

3.The developed methodological tools of prediction analysis of international trade risks, based on probability modelling enables to approach to a complex systematic solution in compliance with the research objectives. This solution is based on the data, taking into consideration both: internal and external risk factors, thus, providing interrelation between international trade strategy of a company and its business activities in the sphere of international trade.

4.Based on the research results, we singled out the factors exerting an impact on the loss probability in case of unfavorable events in the sphere of international trade or fulfillment of contractual obligations, which makes it possible to classify international trade risks. By solving the problems set in research we grounded that multiple factors of risk emergence in the international trade are characteristic for the company operation.

\section{References}

[1] Bets G. Business. Explanatory dictionary [Electronic resource] / G. Bets, B. Brayndli, S. Williams and others; general edition: Doctor of Economics Osadchaya of I.M.//Academician: dictionaries and encyclopedias. URL: http://dic.academic.ru/dic.nsf/business/11576

[2] Financial and credit encyclopedic dictionary [Text] / Collective of authors; under the general editorial office A.G. Gryaznova. M.: Finance and statistics, 2004. 1168 pages.

[3] Krasavina L.N. Problems of updating of conceptual bases of regulation of the external economic risks of Russia in the conditions of integration into world economy and membership of the WTO [Text] / L.N. Krasavina//Money and credit. 2013. № 9. page 10-16.

[4] Labsker L.G. Probabilistic modeling in financial and economic area [Text]: education guidance / L.G. Labsker. 2nd edition. M.: INFRA-M, 2014. 172 pages.

[5] Lopatnikov L.I. Short economic-mathematical dictionary [Text] / L.I. Lopatnikov. M.: Nauka publishing house, 1979. page 358.

[6] Martyanova O.V. Application of probabilistic models for efficiency analysis of the foreign trade strategy of the organization in the conditions of uncertainty [Text] / O.V. Martyanova // Audit and financial analysis. 2016. № 2. page 101-109. 